\title{
Endoscopic Services in the United States: By Whom, for What, and Why?
}

\author{
James W. Feimster, MD, and John D. Mellinger, MD, FACS
}

(J Am Board Fam Med 2019;32:454-456.)

The Peterson et $\mathrm{al}^{1}$ article in the Journal examines the declining volume of endoscopic procedures performed by family physicians (FPs) in both urban and rural settings. In a relatively short, 3-year time period, the percentage of colonoscopies, sigmoidoscopies, and upper endoscopies performed by rural FPs declined by half. Urban FPs performed fewer endoscopic procedures overall in comparison to their rural counterparts; however, they also experienced a statistically significant decline in sigmoidoscopies and endoscopies over the study interval. This commentary will focus on the relevance of this issue from the standpoint of health care delivery with particular reference to colorectal cancer (CRC) screening, assessments of endoscopic quality, and potential solutions, including training paradigms in flexible endoscopy.

\section{Importance of Endoscopic Screening}

While a variety of diseases are managed diagnostically and therapeutically through flexible endoscopy, colorectal neoplasia is demographically the most important. CRC screening specifically remains a high priority as it is the third most common cancer in men and women in the United States. ${ }^{2} \mathrm{~A}$ number of modalities are available for CRC screening, ${ }^{3,4}$ but $62 \%$ of patients choose screening

From the Department of Surgery, Southern Illinois University School of Medicine, Springfield, IL.

Funding: none.

Conflict of interest: none declared.

Corresponding author: John D. Mellinger, MD, FACS, J. Roland Folse Endowed Chair in Surgery, Vice Chair, Department of Surgery, Professor and Chair of General Surgery, SIU School of Medicine, PO Box 19638, 701 N. First St., Springfield, IL 62794-9638 (E-mail: jmellinger@siumed. edu).

\section{See Related Article on Page 460.}

colonoscopy. ${ }^{3}$ The advantages of colonoscopy are several, including a high sensitivity for detecting cancer and adenomas, the potential for synchronous diagnosis and treatment, and intervals of 10 years between interventions following normal examinations in average risk settings. ${ }^{4}$

\section{Assessing Endoscopic Quality}

The quality of colonoscopy is critical in achieving the overall goal of screening, namely reduction in cancer risk. The adenoma detection rate (ADR) is a quality measure defined as the proportion of screening colonoscopies that detect at least 1 adenoma or CRC. Corley et $\mathrm{al}^{5}$ studied more than 250,000 colonoscopies with a 10-year follow-up period and demonstrated that the $\mathrm{ADR}$ was inversely associated with risk for interval CRC. Specifically and powerfully, for every $1 \%$ increase in $\mathrm{ADR}$, there was a corresponding $3 \%$ decrease in CRC. ${ }^{5}$

Another quality measure of adequate endoscopic evaluation of the colon is the withdrawal time, defined as the time from cecal intubation to the point when the colonoscope is completely removed from the rectum. ${ }^{7}$ A mean withdrawal time of at least 6 minutes has been recommended by a multisociety task force. ${ }^{8}$ Barclay et $\mathrm{al}^{7}$ evaluated 2053 screening colonoscopies performed by 12 experienced gastroenterologists and found an almost linear relationship between withdrawal time and neoplasia detection rates. In addition, advanced neoplasia was detected more frequently in colonoscopies that had longer withdrawal times.

The adequacy of the bowel preparation before screening colonoscopy has also been shown to be related to the overall quality and yield of endoscopic evaluation. Failure to adequately prepare the colon can lead to missed lesions and the need for repeat colonoscopies at earlier intervals. ${ }^{9}$

In summary, to achieve the public health goal of colonoscopy, namely reduction of CRC, it is ap- 
parent that inspection quality as reflected by prep adequacy and withdrawal time, and cancer precursor recognition and management as reflected by ADR, be consistently achieved.

\section{Who Should Provide Endoscopic Services}

Endoscopic services are currently performed by gastroenterologists, surgeons, FPs, and advanced practice providers throughout the United States. The American Society for Gastrointestinal Endoscopy (ASGE) and American Board of Surgery (ABS) have recently documented their respective stances on training endoscopic practitioners. These stances have not been in full agreement, with contrasting literature being cited by various groups. ${ }^{11}$ The ASGE recommendations currently require a minimum of 130 esophagogastroduodenoscopy (EGDs) with successful intubation of the esophagus and pylorus in over $95 \%$ of cases, and 275 colonoscopies with a cecal intubation rate of $90 \%$ as a beginning experience for entertaining competence. ${ }^{12}$ The limitations of a purely number-based approach to competence are well recognized by all societies, as learning curves across many procedural domains including endoscopy are clearly dependent on individual as well as educational variables. ${ }^{13}$

The ABS recently emphasized the foundational importance of competency rather than volume-only based resident training. Their recertification case log data demonstrates a high reliance on surgeons in the provision of endoscopic services, especially in rural areas. ${ }^{11}$ In the United States, $39.8 \%$ of a general surgeons' procedural practice in rural and underserved areas involves flexible endoscopic procedures. In Canada, surgeons were found to be the primary physicians providing flexible endoscopic services in rural areas. ${ }^{14,15}$ The ABS requires that all graduating general surgery residents achieve the endoscopic case volume minimum requirements of the Residency Review Committee for Surgery of the Accreditation Council for Graduate Medical Education, specifically to include 35 esophagogastroduodenoscopies and 85 colonoscopies by the completion of a 5 -year residency. The ABS has also sanctioned a standardized scoring tool assessing performance on such clinical endoscopic procedures as a required assessment for all residents nationwide. ${ }^{16}$ Within the past several years the ABS, in collaboration with The Society of American Gastrointestinal and Endoscopic Surgeons, has developed a curriculum to improve endoscopic train- ing in surgical residencies called Fundamentals of Endoscopic Surgery. This curriculum, required of all general surgery residents nationwide for board examination eligibility, includes Web-based didactics in flexible endoscopy as part of a longitudinal curricular strategy over the course of a 5 year residency, and culminates in a high-stakes cognitive and technical examination, the latter being performed on a virtual reality simulator. ${ }^{11}$

FPs trained in endoscopic services, as mentioned in this article of the fournal, can provide CRC screening, and perform approximately $2 \%$ of all colonoscopies in the United States. ${ }^{17} \mathrm{Sev}$ eral studies have shown that FPs and primary care physicians (PCPs), particularly when a specialist is on standby, can achieve the same benchmarks of endoscopic quality, including ADR, as compared with experienced gastroenterologists. ${ }^{17-20}$ A meta-analysis performed by Wilkins et $\mathrm{al}^{18}$ examined 18,292 patients who underwent colonoscopy performed by PCPs. The mean estimated ADR was $28.9 \%$ and major complication rate was $0.04 \%$. They concluded that PCPs are able to achieve quality and safety metrics comparable to those of other providers, as advocated for by associations including ASGE, the American College of Gastroenterology, and Society of American Gastrointestinal and Endoscopic Surgeons. ${ }^{18}$

Lastly, nonphysicians (ie, nurses, nurse practitioners, and physician assistants) have been studied in their performance of upper and lower endoscopies. A systematic review and meta-analysis in 2014 demonstrated that the majority of studies involving nonphysician performance of endoscopy focused on flexible sigmoidoscopy for CRC screening. The adverse event rate was 0.3 per 1000 sigmoidoscopies with adenoma detection rates ranging from $9.9 \%$ to $23.7 \%$. In those studies that included colonoscopies performed by nonphysicians $(\mathrm{n}=3)$, the cecal intubation rate was $93.5 \%$, ADR was $26.4 \%$, and adverse event rate 2.2 per 1000 colonoscopies. The meta-analysis concluded that nonphysicians can perform endoscopy, particularly sigmoidoscopies, with similar outcomes and adverse events compared with physicians. ${ }^{21}$ The expanded use of endoscopic techniques by FPs, other PCPs, and nonphysicians may allow for wider access of CRC screening throughout the US, especially in rural and underserved areas. 


\section{Ways Forward}

Endoscopic services continue to be vital in screening programs for CRC, as well as in diagnosing and treating other common and demographically important gastrointestinal pathologies. No matter who the provider of endoscopic services is, access to these services, especially in rural and underserved areas is vital to public health. Standardized competency-based strategies, of which Fundamentals of Endoscopic Surgery is a prototype, coupled with ongoing practice performance benchmarking and quality assurance measures, can serve to ensure access, including in areas that are underserved by specialty providers. To achieve the goals of endoscopic care, and especially with reference to the demographically important area of CRC screening, it is critical that any and all providers be capable of and accountable to quality benchmarks, and able to provide appropriate intervention for the pathology identified so as to avoid unnecessary duplication of procedures. In the authors' opinion, FPs can, and in all likelihood should remain part of that equation, given their demonstrated commitment as a specialty to all segments of the population served.

To see this article online, please go to: http://jabfm.org/content/ 32/4/454.full.

\section{References}

1. Peterson LE, Nasim U, Madabhushi V. Declining endoscopic care by family physicians in both rural and urban areas. J Am Board Fam Med 2019;32;460-61.

2. Siegel RL, Miller KD, Fedewa SA, et al. Colorectal cancer statistics, 2017. CA Cancer J Clin 2017;67:177193.

3. Lin J, Piper M, Perdue L, et al. Screening for colorectal cancer: A systematic review for the U.S. Preventive Services Task Force. Evidence synthesis No. 135. AHRQ publication No. 14-05203-EF-1. Rockville, MD: Agency for Healthcare Research and Quality; 2016.

4. Rex D, Boland R, Dominitz J, et al. Colorectal cancer screening: Recommendations for physicians and patients from the U.S. Multi-Society Task Force on Colorectal Cancer. JAMA 2016;315:2595-2609.

5. Corley DA, Jensen CD, Marks AR, et al. Adenoma detection rate and risk of colorectal cancer and death. N Engl J Med 2014;370:1298-1306.

6. O'Brien M, Winawer SJ, Zauber AG, et al. The National Polyp Study. patient and polyp characteristics associated with high-grad dysplasia in colorectal adenomas. Gastroenterology 1990;98:371-379.

7. Barclay RL, Vicari JJ, Doughty AS, Johanson JF, Greenlaw RL. Colonoscopic withdrawal times and adenoma detection during screening colonoscopy. N Engl J Med 2006;355:2533-2541.

8. Rex DK, Bond JH, Winawer S, et al. Quality in the technical performance of colonoscopy and the continuous quality improvement process for colonoscopy: recommendations of the U.S. Multi-Society Task Force on Colorectal Cancer. Am J Gastroenterol 2002;97:12961308.

9. Lai EJ, Calderwood AH, Doros G, Fix OK, Jacobson BC. The Boston Bowel Preparation Scale: a valid and reliable instrument for colonoscopy-oriented research. Gastrointest Endosc 2009;69:620-625.

10. Johnson DA, Barkun AN, Cohen LB, et al. Optimizing adequacy of bowel cleansing for colonoscopy: recommendations from the US multi-society task force on colorectal cancer. Gastroenterology 2014;147:903-924.

11. Hazey JW, Marks JM, Mellinger JD, et al. Why fundamentals of endoscopic surgery (FES)? Surg Endosc 2014;28:701-703.

12. Faulx AL, Lightdale JR, Acosta RD, et al. Guidelines for privileging, credentialing, and proctoring to perform GI endoscopy. Gastrointest Endosc 2017;85:273-281.

13. Wani S, Hall M, Wang A, et al. Variation in learning curves and competence for ERCP among advanced endoscopy trainees by using cumulative sum analysis. Gastrointest Endosc 2016;83:711-719.e11.

14. Harris JD, Hosford CC, Sticca RP. A comprehensive analysis of surgical procedures in rural surgery practices. Am J Surg 2010;200:820-825; discussion 825-826.

15. Hilsden RJ, Tepper J, Moayyedi P, Rabeneck L. Who provides gastrointestinal endoscopy in Canada? Can J Gastroenterol 2007;21:843-846.

16. Vassiliou MC, Kaneva PA, Poulouse BK, et al. Global Assessment of Gastrointestinal Endoscopic Skills (GAGES): a valid measurement tool for technical skills in flexible endoscopy. Surg Endosc 2010;24:1834-1841.

17. Xirasagar S, Hurley TC, Sros L, Herbert JR. Quality and safety of screening colonoscopies performed by primary care physicians with standby specialist support. Med Care 2010;48:703-709.

18. Wilkins T, LeClair B, Smolkin M, et al. Screening colonoscopies by primary care physicians: a metaanalysis. Ann Fam Med 2009;7:56-62.

19. Holub J, Morris C, Fagnan L, Logan J, Michaels L, Lieberman D. Quality of colonoscopy performed in rural practice: experience from the clinical outcomes research initiative and the Oregon Rural Practice-based Research Network. J Rural Health 2018;34:75-83.

20. Kolber M, Olivier N, Babenko O, Torrie R, Green L. Alberta Family Physician Electronic Endoscopy study: quality of 1769 colonoscopies performed by rural Canadian family physicians. Can Fam Physician 2018;64:553-560.

21. Day LW, Siao D, Inadomi JM, Somsouk M. Nonphysicians performing lower and upper endoscopy: a systematic review and meta-analysis. Endoscopy 2014;46:401-410. 